\title{
The Linguistic Enlightenment Level of Eleventh (11th) Grade Students in Jordan and its Relationship with Some Variables
}

\author{
Abed Al-Salam Y. Al-Ja' afra ${ }^{1} \&$ Reda S. ALmawdieh ${ }^{1}$ \\ ${ }^{1}$ The Faculty of Educational Sciences, Zarqa University, Zarqa, Jordan \\ Correspondence: Reda S. ALmawdieh, The Faculty of Educational Sciences, Zarqa University, Zarqa, Jordan \\ ON., A346, Jordan. Tel: 962-0538-21100-1603. E-mail: radamwdiah@yahoo.com
}

Received: February 3, 2018 Accepted: February 9, 2018 Online Published: February 28, 2018

doi:10.5539/mas.v12n3p153 URL: https://doi.org/10.5539/mas.v12n3p153

\begin{abstract}
The present study aimed at identifying the linguistic enlightenment level of eleventh 11th grade students in Jordan. The study's sample consisted from two hundred (200) female and male students who were selected through using the random stratification method from Al-Karak public schools at Jordan. In order to fulfill the study's objectives, the researchers of the current study prepared a multiple - choice objective test that consisted from fifty (50) items. Each item includes four (4) choices. Those items cover three linguistic systems of Arabic: the syntactic, morphological and semantic systems. The study's results showed that students showed a low linguistic enlightenment level in the aforementioned linguistic systems. That was concluded through having an arithmetic mean of (27.52) and a relative weight of (55.04) \%. The results also showed that there isn't any statistically significant difference between students' linguistic enlightenment levels - at the significance level of $(a \geq 0.05)$ - which can be attributed to their academic stream (i.e. the scientific or literary stream). The results also showed that there are statistically significant differences between students' linguistic enlightenment levels at the significance level of $(a \geq 0.05)$ - which can be attributed to their gender in syntax, and morphology. The latter differences were for the favor of female students. However, there isn't any statistically significant difference between students' linguistic enlightenment levels - at the significance level of $(a \geq 0.05)-$ which can be attributed to their gender in semantics.
\end{abstract}

Keywords: enlightenment level, linguistic enlightenment, eleventh (11th) grade

\section{Introduction}

\subsection{The Problem}

Enlightenment has been attracting much attention by researchers and students in various disciplines. That is attributed to its significance in upbringing the individual on the scientific, health, social, psychological, and linguistic levels in the light of the current era which is characterized with having rapid changes and developments. The term "enlightenment" appeared in Europe as a way of representing the ideologies that are characterized with having humanitarian, scientific and rational tendencies. Later on, the meaning of this concept expanded. For instance, it started to refer to the methods and means through which the individual expresses his understanding for the world and the roles he should play in it. In other words, it is an image for the individual's life through which the elements of the language he uses complement his acts, values, beliefs, knowledge and social attitudes which distinguish him from others in general and the ones who belong to his culture in particular.

Linguistic enlightenment consists from three main dimensions. The first dimension is the cognitive dimension which includes the knowledge, information, concepts, and rules that are related to Arabic language. The second dimension is the skills dimension which includes the mental, practical and social skills that are necessary for comprehending the language and dealing with it. The third dimension is the sentimental dimension which is represented in all the outcomes that are related to the passionate emotional aspect, such as: one's values, attitudes and tendencies towards language and awareness about its significance (Hamoudeh et al., 2012; Al-Twaijari, 2002).

There are various factors that participate in promoting linguistic enlightenment within the student. Such factors may include: student's family, media and the nature of the community he is living in. It should be noted that school - represented by its teachers - play the most significant role in promoting the linguistic enlightenment 
within the student (Doveston, 2007). That is because teachers play the most significant role in making students comprehend the curriculum and fulfilling the sought outcomes from the concerned curriculum. Therefore, teachers must make students acquire some essential expertise related to Arabic language, such as: understanding its nature and its relationship with work and society, following up its developments and changes, identifying the problems and threats facing it, and analyzing the reasons and consequences of such problems and threats. Such essential expertise also include: learning how to make the right decisions related to this language, and mastering its main skills (listening, speaking, writing and reading). Teacher must also promote awareness among students about the significance of Arabic language and its role in life and the way it can be employed to solve their problems and achieve their well-being in a proper manner (Abu Odeh, 2006).

Language is considered one of the most significant requirements for achieving self-realization, and realizing one's own identity and existence (Al-A'mayrah, 2002). It is also considered a distinguished social phenomenon. To be more specific, it is considered the most significant phenomenon that the human race has achieved throughout history. That is because it reflects the society's identity and is considered one of the elements that participate in unifying the society. It gained such significance because it is a method used for expressing ideologies, communicating and sharing knowledge. For instance, humans use it to express their ideas and feelings. Through it, people shall be able to communicate with each other. It also represents a mirror that reflects one's mind because it is closely linked to one's ideology. It's also an intellectual tool that one uses to realize things and concepts and conduct operations (Salem, 2003).

Acquiring language skills - especially the reading and writing skills - is considered a significant predicator indicating that the student shall succeed in his later academic stages. Therefore, making students acquire such skills became a national target in many countries due to their significance in integrating one in the society on the economic, social and cultural levels. Acquiring language skills requires having teachers who are highly aware about the significance of such skills and informative about them. That is because teachers are considered the most significant source for promoting linguistic enlightenment among students (Karen, 2008; Aram, 2004).

The overall linguistic system consists from sub-systems. Such sub-systems include the sound system (i.e. the phonological system) which identifies the way words and their parts are pronounced in accordance with the patterns that are commonly known among the members of certain group. Linguistic sub-systems also include the semantic system which is concerned with the order of semantic units in accordance with their semantic characteristics that are commonly known. Linguistic sub-systems also include the syntactic system which is concerned with the order of words in a sentence in accordance with the identified or commonly known syntactic structure of the concerned language. Linguistic sub-systems also include the morphological system which is concerned with the structure, types, and derivations of words. Such sub-systems include the lexicographical system which refers to the overall words that are available in language which carry certain meanings and refer to certain contexts. Each system of those linguistic sub-systems is governed by its own functions, rules and regulations. They all complement one another to order words in an organized manner to produce a correct proper sentence that can deliver the meaning that the speaker has intended it to the listener properly (Zayed, 2011; Hamoudeh et al., 2012).

Using Arabic language in a correct proper manner throughout the various academic stages requires much hard work. It also requires combining efforts on various formal and informal levels. That is because students usually do not comprehend the information they receive about the linguistic disciplines of their language easily and do not show eagerness and excitement to learn such information. Such lack of eagerness, excitement and comprehension can be attributed to various aspects. Such aspects may include aspects related to the Arabic language teachers. For instance, most of those teachers are not able to teach such information in the way it ought to be taught. Therefore, many of the advocates of Arabic language have claimed for giving the Arabic linguistic disciplines the care and attention they desire (Al-Ebrahimi, 2017). Thus, the present study aimed at investigating the linguistic enlightenment level of eleventh (11th) grade students in Jordan.

\subsection{The Importance of the Problem}

Learning Arabic language in its written, read and spoken forms is considered one of the most significant goals that the teaching - learning process in Jordan seeks to achieve. That is because learning the language skills and mastering them are considered the only way for improving the teaching - learning process. Academics have emphasized the significance of making students acquire the Arabic language skills and become enlightened about them. However, there is a great debate between various groups about the extent of students' possession for those skills and the extent of applying them in their daily lives. Opinions on this matter vary. Therefore, the present study aimed at investigating the linguistic enlightenment level of eleventh (11th) grade students in 
Jordan.

The significance of the present study arises from the significance of its field (i.e. the field of Arabic language). For instance, this language represents the Arab nation's identity, and is considered a symbol for its unity and a record for its civilizations. The researchers designed a scale (i.e. a test) that was passed to several arbitrators to measure the linguistic enlightenment level of eleventh (11th) grade students in Jordan. Other researchers can benefit from this scale through using it in similar studies for other academic stages, areas and variables. According to the best of the researchers' knowledge, the significance of the present study arises from being the first study that seeks to identify the linguistic enlightenment level of eleventh (11th) grade students in Jordan. Its significance also arises from seeking to provide suggestions and recommendations that shall be useful for the developers of Arabic language curricula, Arabic language teachers, supervisors, educators and researchers.

\subsection{The Previous Studies}

The researchers of the present study have reviewed several studies that are relevant to the topic of the current study. Such studies include the following:

Al-Dahri (2016) conducted a study titled (The linguistic enlightenment level and its relationship with secondary students' motivation to study Arabic language in Baghdad). The study's sample consisted from four hundred eighty (480) female and male students. In order to fulfill the study's objectives, the latter researcher designed a test that consisted from two parts. The first part is a pre-test and the second is a post-test. Students showed low linguistic enlightenment level. There are also statistically significant differences between students' linguistic enlightenment levels which can be attributed to their gender for the favor of the female students.

Al-Naqah and Al-Abed (2012) aimed at identifying the extent of basic stage students' competency in the listening skills. The study's sample was chosen from two schools located in Khan Younis in Palestine. This sample consisted of forty two (42) ninth grade students and forty four (44) tenth grade students. The latter researchers used a questionnaire and a test to identify the competence level of students in the listening skills. The respondents showed low competence level on all the listening skills, except in the skill of ordering the ideas mentioned in the audio text. The latter study concluded that there are no statistically significant differences between students' competence levels on all the listening skills which can be attributed to their grade.

Salim (2009) conducted a study that aimed to identify the linguistic enlightenment level of eleventh (11th) grade female students in Gaza and its relationship with their attitudes towards Arabic language. The study's sample consisted from two hundred twenty nine (229) female students who were selected from various sections in a purposive manner. The latter researcher used a questionnaire to collect the required data. Respondents showed that they have low linguistic enlightenment level.

Graham\& Marcao (2008) aimed to examine the process of teaching French listening skills to students who showed low competence level. The study's sample consisted from sixty eight (68) students who showed low competence level in French language and were living in England. Respondents showed that they have low competence level in listening skills in the pre-test. However, such level was improved on the post-test after they attended a training program.

Al-Wahidi (2005) aimed to identify the extent of acquisition for the writing skills among the ninth grade students enrolled in the public, private and UNRWA schools of Bait Lahem / Palestine. The study's sample consisted from one hundred eighty eight (188) female and male students. Respondents showed low competence level in the writing skills of Arabic language. The results also showed that there are statistically significant differences between the respondents' competence levels in the writing skills of Arabic language which can be attributed to their gender for the favor of females.

Al-Jabareen (2004) aimed to identify the common syntactic and spelling mistakes among the eleventh (11th) grade students enrolled in the public schools subjected to the authority of South Hebron directorate of education. The study's sample consisted from three hundred (300) eleventh grade female and male students who were selected from the scientific and literary streams. The study's results showed that there are common syntactic and spelling mistakes among the eleventh (11th) grade students. The results also showed that there are statistically significant differences between the respondents' numbers of committed mistake which can be attributed to their gender. Such differences were for the favor of female students. The results also showed that there are statistically significant differences between the respondents' numbers of committed mistake which can be attributed to their academic stream for the favor of the students enrolled in the scientific stream.

All of the aforementioned previous results emphasized the significance of promoting linguistic enlightenment 
among students. All of those studies also showed that there are low linguistic enlightenment among students (Al-Jabareen, 2004; Graham\& Marcao, 2008; Al-Wahidi, 2005; Al-Naqah and Al-Abed, 2012; Al-Dahri, 2016; Salim, 2009). The results of some studies showed that there are statistically significant differences between the respondents' linguistic enlightenment levels which can be attributed to their gender for the favor of the female students (Al-Dahri, 2016; Al-Wahidi, 2005; Al-Jabareen, 2004). The results of some studies showed that there are statistically significant differences between the respondents' linguistic enlightenment levels which can be attributed for their academic stream for the favor of the students enrolled in the scientific stream.

All of the aforementioned studies aimed at investigating the linguistic enlightenment level among the students of the basic educational stage, except for the study of Al-Jabareen (2004) which targeted secondary stage students.

As for the present study, it differs from all of the aforementioned studies in its sample. To be specific, the sample of the current study was chosen from the eleventh (11th) grade students from the scientific and literary streams. They were chosen from the public schools of Karak / Jordan. Thus, no study of the above has targeted such a sample with seeking to investigate the same topic. The present study differs from all of the aforementioned studies in its instrument which was designed by the researchers of the present study. It also differs from the previous studies in the three linguistic systems it covers; the syntactic, morphological and semantic systems.

\subsection{The Study's Questions, Terms Definition, and the Study's limits}

The present study aimed at identifying the linguistic enlightenment level of eleventh (11th) grade students in Jordan. It also aimed at identifying whether there is any statistically significant difference between students' linguistic enlightenment levels which can be attributed to their academic stream or gender. In order to identify that, the researchers of the current study aimed at providing answers for the following questions:

1) - What is the linguistic enlightenment level of eleventh (11th) grade students in Jordan?

2) - Is there any statistically significant difference between students' linguistic enlightenment levels which can be attributed to their academic stream (the scientific or literary stream)?

3) - Is there any statistically significant difference between students' linguistic enlightenment levels which can be attributed to their gender (female of male)?

Definition of Terms:

1) - Linguistic enlightenment: The basic language skills that students must master. Those elements as a whole represent the students' linguistic knowledge. These skills are: (listening, speaking, writing and reading) (Al-Refa'i, 2008, p. 247).As for the operational definition of this expression, the researchers of the present study define it as being the availability of a certain level of language skills and knowledge among eleventh (11th) grade students in Jordan who are enrolled in the scientific or literary stream in a way that enables them to use Arabic language properly in their daily lives.

2) - The linguistic enlightenment level: This definition is defined operationally by the researchers of the present study as being the total score that the sampled student gets in the linguistic enlightenment scale (i.e. the study's test).

3) - The eleventh (11th) grade: It is the first grade in the secondary stage according to the educational system of Jordan. This grade is preceded by the tenth 10th grade, and is holding the eleventh rank in the public educational system (Al-Zboun et al., 2016, p. 91).

The Study's limits:

The present study is restricted to the following:

1) - The material limit: It refers to the three linguistic systems of Arabic language (i.e. the syntactic, morphological and semantic systems).

2) - The human limit: It refers to eleventh (11th) grade students in Jordan from the scientific and literary streams

3) - The spatial limit: It refers to the male and female secondary schools that are subjected to the authority of the directorates of education of Karak / Jordan

4) - The temporal limit: It refers to the first semester of the academic year $(2016$ / 2017)

\section{Methodology and Procedures}

In order to fulfill the study's objectives, a descriptive approach was adopted because its suits the nature of the study's topic and objectives. 


\subsection{The Study's Population:}

The study's population consisted from all the male and female eleventh (11th) grade students (from the scientific and literary streams) who are enrolled in the public schools that are subjected to the authority of the directorates of education of Karak / Jordan during the first semester of the academic year (2016 / 2017). The study's population included two thousand fifteen (2015) female and male students distributed to forty three (43) secondary schools.

\subsection{The Study's Sample:}

The study's sample consisted from two hundred (200) female and male students who were selected from the scientific and literary academic streams. They are distributed to eight (8) secondary schools in Karak governorate. They were chosen through using the random stratification method. That can be illustrated through table (1) below.

Table 1. The distribution of the study's sample according to their academic stream (Scientific or literary) \& gender

\begin{tabular}{lllll}
\hline The School's Name & Gender & Academic Stream & Frequency & Percentage\% \\
& & & & \\
Al-Karak Secondary School for males & Male & Literary & 25 & $26 \%$ \\
Mu'tah Secondary School for males & Male & Literary & 27 & \\
Abed Al-Wahab Secondary School for males & Male & Scientific & 23 & $22.5 \%$ \\
Al-Safi Secondary School for males & Male & Scientific & 22 & \\
Al-Tiba Secondary School for females & Female & Literary & 21 & $21.5 \%$ \\
Al-Mazra'ah Secondary School for females & Female & Literary & 22 & \\
Noor Al-Hussain Secondary School for females & Female & Scientific & 32 & $30 \%$ \\
& Female & Scientific & 28 & \\
\hline Total & & & 200 & $100 \%$ \\
\hline
\end{tabular}

\subsection{The Study'S Instrument}

The researchers of the present study designed an objective test. Its final form consisted from fifth (50) items. Each item includes four (4) choices. Those items cover three linguistic systems of Arabic: the syntactic, morphological and semantic systems. The syntactic system is covered by twenty four (24) items, whereas the morphological system is covered by a sixteen (16) items. As for the semantic system, it is covered by ten (10) items. The items of this test were formed after reviewing the Arabic language curriculum, the teachers' guide and the general and specific outcomes. The test was designed after reviewing the scales used by other researchers (Salim, 2009; Al-Dahri, 2016; Bacanak and Gokdere, 2009; A'lam Al-Deen, 2007; Al-Refa'i, 2008, Al-Swairki, 2014). When drafting the test's items, the researchers of the present study decided to choose a standard form for all the items to ensure that the students shall concentrate and their concentration won't be dispersed. The researchers of the present study were also keen to making a balance in the length of the given choices and making sure that only one answer is correct.

The test forms were passes to an exploratory sample that was selected from the study's population, but not from the study's sample. This exploratory sample consisted from thirty five (35) students. The test forms were passed to the exploratory sample to identify the extent of their comprehension for the test's items and instructions. They were passed to them to identify the time needed for doing the test and measuring its validity and reliability. In order to calculate the time needed for the answering all the items, the arithmetic mean of the time needed by the first five students was calculated. It is 30 minutes. Then, the mean of the time needed by other five students was calculated and it is 60 minutes. After that, the total arithmetic mean was calculated and it is 45 minutes.

\subsection{The Instrument's Validity:}

In order to measure the test's validity, it was passed - in its initial form - to ten (10) arbitrators. Three (3) of them are specialized in the field of Arabic language and teach Arabic language to secondary stage students. The arbitrators also include supervisors and educators for the Arabic language course. These arbitrators also include three (3) university professors who teach curricula and teaching methods of Arabic language in Jordanian universities and two (2) university professors who are specialized in assessment and measurement. The initial 
form of this test consisted from fifty four (54) items. In the light of the arbitrators' recommendations and suggestions, several deletions, additions, and modifications were made to produce the final form of the test. The final form of the test consisted from fifty (50) items.

\subsection{The Test's Reliability:}

In order to measure the test's reliability, the split half method was used. Pearson correlation coefficient was also calculated between the total sum of odd scores and the total sum of even scores - the split half method. The value of the Pearson correlation coefficient is (0.64). After that, it was corrected through Spearman's rank correlation coefficient. The total reliability coefficient of the test is $(0.78)$. This value reflects that the test is relatively highly reliable.

\subsection{The criterion adopted for classifying the scores and method of correction:}

One score was given for each item. In case the student answered the item correctly, he / she shall get one score. In case he answered the item wrong, he / she shall get a zero. Thus, the maximum score of the test is 50 with covering three linguistic systems of Arabic; the syntactic (24 score), morphological (16 scores) and semantic and lexicographical (10 scores) systems. The student would obtain 50 scores in case he answered all the test's items correctly. He / she shall get a zero in case all of his / her answers are wrong. A model answers sheet was set to facilitate the process of correcting the students' answers sheets.

After reviewing the relevant previous studies and the opinions of specialists and educators, the following criterion was adopted to identify the linguistic enlightenment level of the respondents:

Less than $60 \%$ is classified as low

$60 \%-80 \% \%$ is classified as moderate

More than $80 \% \%$ is classified as high

\subsection{The Study's Variables:}

1) - The independent variables: Gender (i.e. male and female); The academic stream (i.e. the scientific and literary streams)

2) - The dependent variables: The linguistic enlightenment level of the eleventh (11th) grade students.

2.8 The Study's Procedures:

1) -The researchers of the present study reviewed the educational studies that are relevant for the study's topic

2) -The researchers of the present study reviewed some Arabic language curricula and their objectives.

3) -The researchers of the present study developed an instrument for measuring the students' linguistic enlightenment level (which is a test)

4) -In order to check the test's validity, it was passed to a group of arbitrators who are specialized in relevant specialties

5) -The coefficients of difficulty and discrimination were calculated for the test's items

6) -The number of the study's population was identified through referring to the directorates of education of Karak / Jordan.

7) -In order to measure the test's reliability, the test forms were passed to an exploratory sample that are chosen from the population, but not from the sample.

8) -The test forms were passed to the study's sample that was chosen through the random stratification method.

9) -The required data was collected and encoded. After that, it was administered into the SPSS program to be processed statistically.

10) -The results were presented, discussed \& interpreted. In the light of those results, recommendations were suggested.

\subsection{The Statistical Processing Methods:}

In order to fulfill the study's objectives and answer the study's questions, the researchers of the present study used the SPSS program, and calculated the arithmetic means and standard deviations. In addition, the researchers conducted the independent samples t-test and one way analysis of variance (ANOVA). 


\section{Results and Discussion}

\subsection{Results Related to the First Question and Discussion:}

Question (1): What is the linguistic enlightenment level of eleventh (11th) grade students in Jordan?

In order to answer question (1), the arithmetic means, standard deviations and relative weight were calculated and the total score was identified. In addition, the three linguistic systems were ranked according to the students' enlightenment level on each. That can be illustrated through table (2)

Table 2. The arithmetic means, standard deviations, relative weight, the total score and the rank of each linguistic system according to the students' enlightenment level about them.

\begin{tabular}{|c|c|c|c|c|c|}
\hline $\begin{array}{l}\text { The sub-systems linguistic } \\
\text { system }\end{array}$ & $\begin{array}{l}\text { Maximum } \\
\text { Score }\end{array}$ & $\begin{array}{l}\text { Arithmetic } \\
\text { Mean }\end{array}$ & $\begin{array}{l}\text { Standard } \\
\text { Deviation }\end{array}$ & $\begin{array}{l}\text { Relative } \\
\text { Weight }\end{array}$ & Rank \\
\hline Syntax & 24 & 13.28 & 2.42 & $55.33 \%$ & 2 \\
\hline Morphology & 16 & 8.94 & 1.64 & $55.81 \%$ & 1 \\
\hline Semantics and Lexicography & 10 & 5.30 & 1.37 & $53 \%$ & 3 \\
\hline Total & 50 & 27.52 & 3.43 & $55.04 \%$ & \\
\hline
\end{tabular}

Through table (2), it can be noticed that the total arithmetic mean of the three linguistic sub-systems is (27.52) from the maximum score (50). As for the total standard deviation, it is 3.43 and the total relative weight is $55.05 \%$. Based on the total score of students' linguistic enlightenment, students showed low linguistic enlightenment level.

The arithmetic means are within the range of $(5.30-13.28)$ and the relative weights are within the range of (53\%- $55.81 \%$ ). The morphological system was ranked first with having an arithmetic mean of 8.93 , a standard deviation of 1.638 and a relative weight of $55.81 \%$.

The syntactic system was ranked the second with having an arithmetic mean of 13.27, a standard deviation of 2.42 and a relative weight of $55.33 \%$. As for the semantic system, it held the third ranked (i.e. the last rank) with having an arithmetic mean of 5.30, a standard deviation of 1.37 and a relative weight of $53 \%$. All of those values are considered low.

This result is considered in agreement with results concluded by (Al-Jabareen, 2004; Al-Wahidi, 2005; Salim, 2009; Al-Naqah and Al-Abed, 2012; Al-Dahri, 2016). However, it is not in agreement with the results concluded by Kuiper (2001). For instance, the study of Kuiper (2001) showed that students showed a high linguistic enlightenment level.

The researchers of the present study attribute this result to several reasons. Such reasons may include: the adoption of traditional teaching methods that depend on recitation and memorization. Such teaching methods are adopted by most Arabic language teachers. Such reasons also include the perception of language as being a group of facts that students must memorize. However, language should be perceived as being a habit that is practiced among other life functions like any other life skill that one acquires. Such reasons include the nature of the curricula. For instance, curricula are developed in a way that makes the teacher teach the language skills separately from one another. However, such skills should be taught as being a single unit because they are integral units and separating them should be formal. Such reasons include the absence of the practical application of classical Arabic language in situations that fulfill students' desires and make them excited. In fact, memorization makes students develop negative feelings towards Arabic language.

One of the most significant reasons for having poor linguistic knowledge about Arabic language is teaching it as being a course like any other course; neither perceiving it from religious perspective nor a national one. From a religious perspective, Arabic language is the language of the Holy Quran. From a national perspective, it is the language shared between members of the Arab nation. It is also considered one of the most significant requirements for achieving unity between those members and one of the most significant factors for achieving bonds between those members. In addition, previous studies showed that there is a strong relationship between students' language competency and their achievement level in various academic courses.

In addition, one should pay attention to the role of media - in its various forms - in promoting linguistic knowledge among students. For instance, media usually uses colloquial language that is not subjected to the rules of classical Arabic language. Such media participated in developing negative attitudes towards Arabic 
language among students. The researchers of the present study believe that there is a strong relationship between the decline of the Arab nation currently and the status of the Arab language. That is because Arabic language develops and flourishes with the advancement of the culture and civilization of the members of that language.

\subsection{Results Related to the Second Question and Discussion:}

Question (2): Is there any statistically significant difference between students' linguistic enlightenment levels which can be attributed to their academic stream (the scientific or literary stream)?

In order to answer question (2), the researchers of the present study conducted the independent samples t-test. It was conducted to identify the differences between the students' linguistic enlightenment levels which can be attributed to their academic stream (the scientific or literary stream). That can be illustrated through table (3) below:

Table 3. The arithmetic means and standard deviations of the students' scores in the test in each linguistic system and the systems as a whole in accordance with the academic stream (the scientific and literary streams)

\begin{tabular}{lllll}
\hline The linguistic sub-system & Academic Stream & Frequency & Arithmetic Mean & Standard Deviation \\
\hline Syntax & Scientific & 105 & 13.38 & 2.292 \\
& Literary & 95 & 13.17 & 2.554 \\
\hline Morphology & Scientific & 105 & 8.91 & 1.605 \\
& Literary & 95 & 8.96 & 1.681 \\
\hline \multirow{2}{*}{ Semantics and Lexicography } & Scientific & 105 & 5.33 & 1.349 \\
& Literary & 95 & 5.27 & 1.337 \\
\hline \multirow{2}{*}{ Total } & Scientific & 105 & 27.63 & 3.337 \\
& Literary & 95 & 27.40 & 3.547 \\
\hline
\end{tabular}

Through table (3), it can be noticed that there are superficial differences between the means of the scores of the students enrolled in the scientific stream and the ones enrolled in the literary stream in each system and the systems as a whole. For instance, the total arithmetic mean of the scores of the students in the scientific stream is (27.63) with having a standard deviation of (3.337). The total arithmetic mean of the scores of the students in the literary stream is (27.40) with having a standard deviation of (3.547). In order to identify the statistical significance of those differences, one way analysis of variance (ANOVA) was conducted in accordance with the students' academic stream. That can be illustrated through table (4) below:

Table 4. The source of variation, sum square (SS), degree of freedom (DF), mean square (MS), F value, and the significance level (Sig.) in accordance with variable of the academic stream

\begin{tabular}{|c|c|c|c|c|c|c|}
\hline $\begin{array}{l}\text { The } \\
\text { sub-system }\end{array}$ & $\begin{array}{l}\begin{array}{l}\text { Source } \\
\text { variation }\end{array} \\
\text { of }\end{array}$ & $\begin{array}{l}\text { Sum Square } \\
\text { (SS) }\end{array}$ & $\begin{array}{ll}\text { Degree } & \text { of } \\
\text { Freedom }(D F)\end{array}$ & $\begin{array}{l}\text { Mean Square } \\
(M S)\end{array}$ & $\begin{array}{l}F \\
\text { Value }\end{array}$ & Sig. \\
\hline \multirow[t]{3}{*}{ Syntax } & Among group & 2.253 & 1 & 2.253 & 0.385 & 0.536 \\
\hline & Within group & 1160.067 & 198 & 5.859 & & \\
\hline & Total & 1162.320 & 199 & & & \\
\hline \multirow[t]{3}{*}{ Morphology } & Among group & 0.095 & 1 & 1.605 & 0.035 & 0.851 \\
\hline & Within group & 534.060 & 198 & 1.681 & & \\
\hline & Total & 534.155 & 199 & & & \\
\hline \multirow[t]{3}{*}{$\begin{array}{l}\text { Semantics } \\
\text { Lexicography }\end{array}$} & Among group & 0.177 & 1 & 0.177 & 0.094 & 0.759 \\
\hline & Within group & 372.218 & 198 & \multirow{2}{*}{1.880} & & \\
\hline & Total & 372.395 & 199 & & & \\
\hline \multirow[t]{3}{*}{ Total } & Among group & 2.606 & 1 & 2.606 & \multirow[t]{3}{*}{0.220} & \multirow[t]{3}{*}{0.639} \\
\hline & Within group & 2341.314 & 198 & 11.825 & & \\
\hline & Total & 2343.920 & 199 & & & \\
\hline
\end{tabular}

Through table (4), it can be noticed that there isn't any statistically significant difference between students' linguistic enlightenment levels - at the significance level of $(a \geq 0.05)$ - which can be attributed to their academic stream (i.e. the scientific or literary stream). That applies on each system and the systems as a whole. This result 
is not in agreement with the result of Al-Jabareen (2004). That is because the study of Al-Jabareen (2004) showed that there are statistically significant differences between students' linguistic enlightenment levels which can be attributed to their academic stream for the favor of the students enrolled in the scientific stream.

The researchers of the present study attribute the latter result to several reasons. Such reason includes having similar academic conditions surrounding the students in the scientific stream and the ones in the literary stream. Such conditions include the teachers' academic qualifications. The teachers who teach the students in the scientific stream are often the same ones who teach the students in the literary stream. Such conditions include having similar material conditions surrounding the students in the scientific stream and the ones in the literary stream. Such material conditions include the buildings, classrooms, technological instruments used for education, etc...

\subsection{Results Related to the Third Question and Discussion:}

Question (3): Is there any statistically significant difference between students' linguistic enlightenment levels which can be attributed to their gender (female of male)?

In order to answer question (3), the researchers of the present study conducted the independent samples t-test. It was conducted to identify the differences between students' scores which can be attributed to their gender (female or male). That can be illustrated through table (5) below:

Table 5. The arithmetic means and standard deviations of the respondents' scores on the test in each linguistic system and the systems as a whole in accordance with their gender (female or male)

\begin{tabular}{lllll}
\hline The linguistic sub-system & Gender & Frequency & Arithmetic Mean & Standard Deviation \\
\hline Syntax & Male & 97 & 12.58 & 2.030 \\
& Female & 103 & 13.94 & 2.569 \\
\hline Morphology & Male & 97 & 8.44 & 1.561 \\
& Female & 103 & 9.40 & 1.580 \\
\hline \multirow{2}{*}{ Semantics and Lexicography } & Male & 97 & 5.19 & 1.210 \\
& Female & 103 & 5.42 & 1.498 \\
\hline \multirow{2}{*}{ Total } & Male & 97 & 26.21 & 3.142 \\
& Female & 103 & 27.40 & 3.240 \\
\hline
\end{tabular}

Based on table (5), it can be noticed that there are superficial differences between the total means of the female and male scores whether in each linguistic system and as the systems as a whole. For instance, the total arithmetic mean of the male students is (26.21) with a standard deviation of (3.142). As for the total arithmetic mean of the female students, it is 28.76 with having a standard deviation of (3.240).

In order to identify the statistical significance of those differences, the researchers conducted one way analysis of variance (ANOVA) in accordance with their gender (males of females). That can be illustrated through table (6)

Table 6. The source of variation, sum square (SS), degree of freedom (df.), mean square (MS), F value, and the significance level (Sig.) in accordance with their gender (female or male)

\begin{tabular}{|c|c|c|c|c|c|c|}
\hline $\begin{array}{l}\text { The linguistic } \\
\text { sub-system }\end{array}$ & $\begin{array}{l}\text { Source of } \\
\text { variation }\end{array}$ & $\begin{array}{l}\text { Sum Square } \\
(S S)\end{array}$ & $\begin{array}{l}\text { Degree of } \\
\text { Freedom }(D F)\end{array}$ & $\begin{array}{l}\text { Mean Square } \\
(M S)\end{array}$ & $\begin{array}{l}F \\
\text { Value }\end{array}$ & Sig. \\
\hline \multirow[t]{3}{*}{ Syntax } & Among group & 92.999 & 1 & 92.999 & 0.000 & $0.000^{*}$ \\
\hline & Within group & 1069.321 & 198 & 5.401 & & \\
\hline & Total & 1162.320 & 199 & & & \\
\hline \multirow[t]{3}{*}{ Morphology } & Among group & 45.537 & 1 & 45.537 & 0.000 & $0.000^{*}$ \\
\hline & Within group & 488.618 & 198 & 2.468 & & \\
\hline & Total & 534.155 & 199 & & & \\
\hline \multirow[t]{3}{*}{$\begin{array}{l}\text { Semantics and } \\
\text { Lexicography }\end{array}$} & Among group & 2.687 & 1 & 2.687 & 1.439 & 0.232 \\
\hline & Within group & 369.708 & 198 & 1.867 & & \\
\hline & Total & 372.395 & 199 & & & \\
\hline Total & Among group & 325.112 & 1 & 325.112 & 31.886 & $0.000^{*}$ \\
\hline
\end{tabular}




\begin{tabular}{cccc}
\hline Within group & 2018.808 & 198 & 10.196 \\
\hline Total & 2343.920 & 199 & \\
\hline
\end{tabular}

Through table (6), it can be noticed that there are statistically significant differences between students' linguistic enlightenment levels - at the significance level of $(a \geq 0.05)$ - which can be attributed to their gender (male or female) in syntax, and morphology. These differences were for the favor of female students. However, there isn't any statistically significant difference between students' linguistic enlightenment levels - at the significance level of $(a \geq 0.05)$ - which can be attributed to their gender in semantics. These results are considered in agreement with the results concluded by (Al-Dahri, 2016; Al-Wahidi, 2005; Salim, 2009; Al-Jabareen, 2004).

The researchers attribute having higher linguistic enlightenment level among females to several reasons. Such reasons include the culture and way of thinking of the people living in Karak. For instance, those people tend to stick to the female related traditions which provide females with more time to study. In addition, the females in that region tend to show more compliance to the rules and regulations. Such reasons also include the increasing demand for education by females and not having any work opportunity available for the females who do not hold any university degree. However, there are work opportunities available in some governmental institutions for the males who do not hold the Tawjihi certificate (i.e. the General Secondary Education Certificate). Such reasons also include the intensity of competition which is greater among females (whether the competition is between teachers or students). In addition, there is a high demand for working in the teaching profession because this profession is accepted by conservative societies. Therefore, it can be noticed that females are showing more interest than males in developing themselves on the academic and professional levels. Such interests shall be reflected on the students' performance.

\section{Recommendations}

The researchers of the present study recommended:

1) - Making guidance programs to promote awareness among students about the significance of Arabic language and its role in their lives.

2) - Encouraging students to use classical Arabic language properly in all the courses rather than using it in the Arabic language course only.

3) - Encouraging Arabic language teachers to focus more on the semantic system because it is the key system that enables one to comprehend the other linguistic systems.

4) - Conducting more studies on other samples to check the reliability of the results of the present study.

\section{References}

Al-Dahri, S. (2016). The linguistic enlightenment level and its relationship with secondary students' motivation to study Arabic language in Baghdad (Unpublished MA thesis). The Middle East Univesity, Amman.

Al-Ebrahimi, M. F. (2017). The linguistic enlightenment level of Arabic language teachers of the primary educational stage. Retrieved from http://www.Qu.eduig/staff/makkikareem/2017/3/30

Al-Jabareen, A. (2004). The common syntactic and spelling mistakes of ninth 9th grade students in the public schools subjected to the authority of South Hebron directorate of education (Unpublished MA thesis). Al-Quds University.

Al-Naqah, S. A., \& Al-Abed, E. S. (2012). The extent of students' competency in the listening skills. The Islamic University Journal, (1), 541-586.

Al-Wahidi, A. Y. (2005). The extent of acquisition for the writing skills among the ninth grade students enrolled in the schools of Bait Lahem (Unpublished MA Thesis). Al-Quds University, Al-Quds.

Hamoudeh, H., Mohammad, A. K., Abu, A. R. H., \& Abu Fraiha, Elham (2012). Arabic language (101) (1st Ed.). Amman, Jordan: Dar Al-Massirah Publishing and Distribution House.

Mohammad, A. A. (2002). Studies in language and education (1st ed.). Amman,Jordan: Dar Wa'el Publishing and Distribution.

Mohammad, A. O. (2006). Assessing the scientific content of the tenth 10th grade technological culture curriculum in the light of the technological enlightenment dimensions (Unpublished MA thesis). The Islamic University of Gaza, Gaza.

Mohammad, A. S. A. (2014). The effectiveness of the language skills curriculum in making new students 
acquires the language skills. The Specialized Educational Journal, 3(12).

Mohammad, A. Z., Al-Ja'afra, A. A. S., \& Al-Mawadieh, R. (2016). The educational system in Jordan (1st ed.). Amman, Jordan: Dar Wa'el Publishing and Distribution.

Mohammad, S. (2003). An analysis for the curriculum (Our Arabic Language) of the sixth grade in Jordan, A research submitted for the curricula development seminar, Foundations and principles - King Saud University, Saudi Arabia.

Zayed, F. (2011). Modern methods for teaching Arabic language ( $1^{\text {st }}$ ed.). Amman, Jordan: Dar Yafa Publishing and Distribution.

\section{Copyrights}

Copyright for this article is retained by the author(s), with first publication rights granted to the journal.

This is an open-access article distributed under the terms and conditions of the Creative Commons Attribution license (http://creativecommons.org/licenses/by/4.0/). 